\title{
Performance Simulation of a Parallel Dual-pressure Once- Through Steam Generator
}

\author{
Yu-Zhi Chen ${ }^{1}$ and Yi-Guang $\mathrm{Li}^{2}$ \\ School of Aerospace, Transport and Manufacturing, Cranfield University, Bedford, UK \\ Mike A Newby ${ }^{3}$ \\ Manx Utilities, Douglas, IM99 19S, Isle of Man, UK
}

\begin{abstract}
The increasing demand for electricity and concern about global warming worldwide mean that electric power generation is required to be more efficient, cleaner, and more cost-effective. Combined-cycle power plants have gradually replaced their simple-cycle counterparts, where the energy of the exhaust gas from prime movers is recovered and used to generate steam and drive steam turbines to generate more useful power. There are two types of devices used to produce steam-one is the conventional drum-type heat recovery steam generator, and the other is the once-through steam generator (OTSG) that has no drum. The performance simulation of the former is relatively mature. However, the performance simulation for the latter is more difficult due to its multi-pressure circuits and moving boundaries between the economizer, evaporator, and superheater in the OTSG. In this research, a novel simulation method for the thermodynamic performance of a parallel dual-pressure OTSG under both design and off-design operating conditions has been developed. The method is applied to an OTSG operating in a combined-cycle gas turbine power plant at Manx Utilities, Isle of Man in the United Kingdom to demonstrate the effectiveness of the simulation method. Meanwhile, the OTSG performance variation caused by inlet gas energy variation and downstream steam turbine erosion are demonstrated. Compared with field data, the simulation results of the OTSG performance show that the novel performance simulation method is successful and provides details of the OTSG thermodynamic performance that may be useful for both OTSG designers and operation engineers.
\end{abstract}

\footnotetext{
${ }^{1} \mathrm{PhD}$ student, School of Aerospace, Transport and Manufacturing, Cranfield University.

${ }^{2}$ Senior Lecturer, School of Aerospace, Transport and Manufacturing, Cranfield University.

${ }^{3}$ Plant Engineering Manager, Manx Utilities.
} 
Keywords: Once-through steam generator, performance, simulation






\section{Greek Letters}

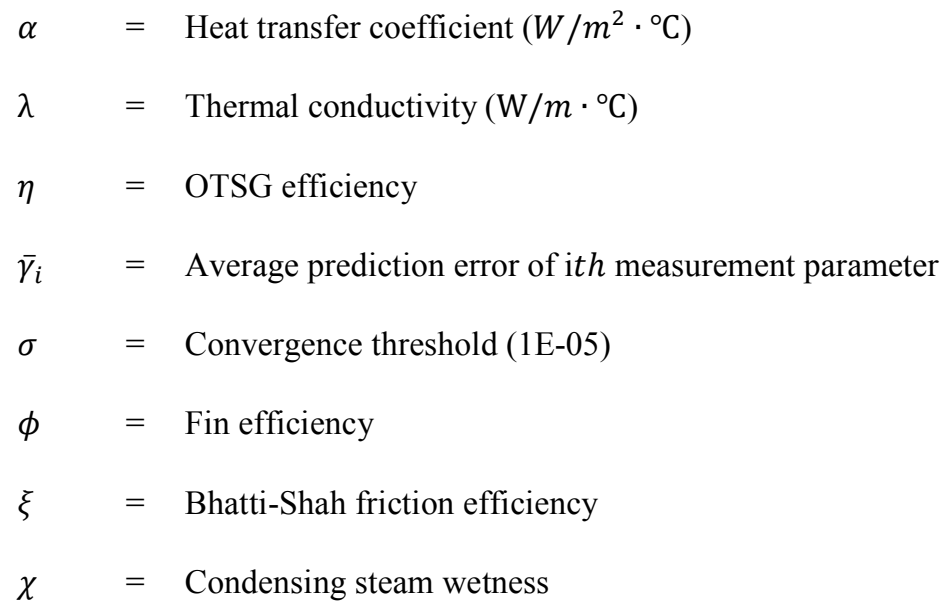

\section{Subscripts}

$$
\begin{array}{ll}
\text { amb } & =\text { Ambient } \\
b & =\text { Bare tube outside } \\
B & =\text { Nucleate boiling } \\
\text { cond } & =\text { Condensing } \\
c o n v & =\text { Convective } \\
D P & =\text { Design point } \\
\text { exh } & =\text { Exhaust } \\
f & =\text { Fin } \\
G T & =\text { Gas turbine } \\
H P & =\text { High pressure } \\
\text { in } & =\text { Inlet } \\
\text { inn } & =\text { Inner side of tubes } \\
L P & =\text { Low pressure } \\
m & =\text { Mean } \\
o & =\text { Outer side of tubes } \\
\text { IP } &
\end{array}
$$




$$
\begin{aligned}
\text { OD } & =\text { Off-design point } \\
\text { out } & =\text { Outlet } \\
s & =\text { Single phase water or steam } \\
S T & =\text { Steam turbine } \\
t & =\text { Tube } \\
T O T & =\text { Total outer tube surface }
\end{aligned}
$$

\section{Superscripts}

$=$ Function's derivative

\section{Introduction}

A heat recovery steam generator (HRSG) is a device that uses the exhaust heat energy from topping cycle as the source of energy to generate steam with high pressure and temperature for process or to drive a steam turbine. Its performance is determined by the thermodynamic conditions of the hot gas and steam flows. A combined-cycle power plant includes three primary units that are gas turbines (GT), steam generators, and steam turbines [1]. There are two kinds of steam generators: a conventional drum-type steam generator, and once-through steam generator (OTSG) without a drum. Many performance simulation models have been successfully developed for the traditional drum-type steam generator [2]-[6] and they are out of the scope of this paper.

Some research on OTSG performance simulation has been done, and the relevant work has been published. Bayless (1979) [7] introduced a performance simulation method for a helically coiled single-pressure OTSG for marine applications where the whole tube is split into equidistant parts, where each part is checked against phase change to determine the rough position of the boundaries between economizer, evaporator, and superheater. Yoon et al. (2000) [8] developed a computer code for design point (DP) performance simulation of a helical OTSG and validated it with available test data. Dumont and Heyen (2004) [9] suggested a two-dimensional simulation method for OTSG DP performance modelling by dividing the OTSG tube into different sections among horizontal and vertical directions. In the above mentioned OTSG models, the simulations are limited to relatively simple single pressure OTSG. 
Ngoma et al. (2003) [10] developed a performance simulation algorithm for sequential dual-pressure OTSG. Hamid et al. (2011) [11] proposed a model for a sequential dual-pressure OTSG by evaluating the effect of steam parameters on CCGT performance when the gas turbine exhaust gas maintains at a base load condition. Although sequential dual pressure OTSGs can recover more heat energy and offer better performance than the single pressure OTSGs, their performance improvement is still limited due to relatively low gas temperature at the exit of high pressure OTSG circuit resulting in poor performance of the downstream low pressure OTSG circuit. Therefore, parallel dual-pressure OTSGs have been developed and offer better performance than their sequential dual-pressure counterparts. However, up to now, no publication has reported the simulation algorithms for the parallel dual pressure OTSGs.

This study introduces a new algorithm to simulate the thermodynamic performance of an OTSG with dual-pressure parallel circuit configuration and moving boundaries between the economizer, evaporator, and superheater. The proposed performance simulation algorithm is validated against field data of an OTSG installed and operated at Manx Utilities (MU) in the Isle of Man, United Kingdom. The DP and off-design (OD) performance of the OTSG and the impact of downstream steam turbine erosion on the OTSG performance are simulated to demonstrate the capability of the method.

\section{Methodology}

The performance calculation of a parallel dual-pressure OTSG can be divided into two steps as follows:

- DP performance calculation, where the OTSG's performance at a specified DP is calculated and critical heat transfer areas are determined;

- OD performance calculation, where the performance of an OTSG under changing exhaust gas and operating conditions is calculated.

\subsection{Geometry Structure and Temperature Profiles}

Figure 1 [12] shows the typical constructive arrangement of a dual-pressure OTSG, and Fig. 2 shows its temperature profiles along the OTSG gas path, where $T_{1}$ is the OTSG inlet gas temperature, $T_{8}$ the stack temperature, $T_{j}$ the HP circuit feed water temperature, and $T_{h}$ the LP circuit feed water temperature. The HP circuit is divided into three sections, namely $(a-d)$ or $(a-b-c-d),(d-i)$ or $(d-m-n-i)$, and $(i-j)$, where part of the HP circuit $(d-i)$ is in parallel to the LP circuit (e-h). The location of the inlets (i.e., points $1, \mathrm{j}$ and $\mathrm{h}$ ) and the outlets (i.e., points 8 , a and e) of the 
gas and steam circuits remain unchanged after being constructed and assembled. Moreover, if two horizontal lines at points $\mathrm{h}$ and e are drawn in Fig.1, the four points (i.e. points $7 \& \mathrm{i}$ and points $4 \& \mathrm{~d}$ ) can be found respectively. As points $\mathrm{h}$ and e (inlet and outlet of the LP circuit) are fixed, the four points (i.e., points 7, i, 4, and d) in the exhaust gas path and in the HP circuit are unchanged for all operating conditions. Therefore, the heat transfer areas of the HP sections $(\mathrm{a}-\mathrm{d}),(\mathrm{d}-\mathrm{i})$, and $(\mathrm{i}-\mathrm{j})$ are unchanged, and their relative positions to the LP circuit are also unchanged. Meanwhile, the heat transfer areas of sections $(\mathrm{e}-\mathrm{h})$ and $(\mathrm{a}-\mathrm{j})$ are the total heat transfer areas of the LP and HP circuits, respectively, and they are unchanged. Hence, even when the boundaries between the economizer, evaporator, and superheater of both the HP and LP circuits in the OTSG are moving, the heat transfer areas of sections (a-d), (d-i), $(\mathrm{i}-\mathrm{j})$, and $(\mathrm{e}-\mathrm{h})$ are unchanged. The heat transfer sections of HP economizer, evaporator, and superheater are (a-b), $(b-c)$, and $(c-j)$ sections respectively, while the heat transfer sections of LP economizer, evaporator, and superheater are $(\mathrm{e}-\mathrm{f}),(\mathrm{f}-\mathrm{g})$, and $(\mathrm{g}-\mathrm{h})$ sections respectively. The temperature slope for the middle section (d-i) of the HP economizer is smaller than that of other parts of the economizer due to lower heat transfer rate because of the adding of the parallel LP circuit. In addition, the heat transfer is balanced between the exhaust gas side and the water or steam sides between any two vertical dash lines, as shown in Fig. 2.

\subsection{Basic Concepts and Definitions}

\subsubsection{Overall Heat Transfer Coefficient}

The overall heat transfer coefficient $U$ of finned tube geometry is calculated by Eq. (1) [13]-[15].

$$
\frac{1}{U}=\frac{1}{\alpha_{o}}+\frac{A_{\text {TOT }}}{A_{\text {inn }}}\left(\frac{1}{\alpha_{i n n}}+\frac{d_{o}-d_{i n n}}{2 \lambda_{t}}\right)
$$

where $\alpha_{i n n}$ is the heat transfer coefficient in the inner tube, $\alpha_{o}$ the virtual heat transfer coefficient at outer side, $\lambda_{t}$ the tube thermal conductivity, $d_{\text {inn }}$ tube inner diameter, $d_{o}$ tube outer diameter, $A_{\text {inn }}$ tube inner surface area, and $A_{T O T}$ the total outer surface area.

\subsubsection{Heat Transfer Coefficient at Outer Side}

The mean heat transfer coefficient at the outer side, $\alpha_{m}$, for cross-flow with staggered banks is estimated using Eq. (2) [9],[13],[16].

$$
\alpha_{m}=0.38 \operatorname{Re}^{0.6}\left(\frac{A_{T O T}}{A_{b}}\right)^{-0.15} \cdot \operatorname{Pr}^{1 / 3} \cdot \frac{\lambda_{\text {exh }}}{d_{o}}
$$


where $R e$ is Reynolds number, $A_{b}$ is bare tube outside surface area, $\operatorname{Pr}$ Prandtl number, and $\lambda_{\text {exh }}$ exhaust gas thermal conductivity. By considering tube fins, $\alpha_{o}$ can be obtained by Eq. (3) [9],[13],[16].

$$
\alpha_{o}=\alpha_{m}\left[1-(1-\phi) \frac{A_{f}}{A_{\text {TOT }}}\right]
$$

where $\phi$ is tube fin efficiency and $A_{f}$ fin surface area.

\subsubsection{Heat Transfer Coefficient at Inner Side}

The calculation of the heat transfer coefficient at the tube inner side $\alpha_{i n n}$ is classified into two scenaria - a singlephase flow (for economizer and superheater) and dual-phase flow (for evaporator). For single phase flow, the heat transfer coefficient is calculated by Eq. (4) [9],[17].

$$
\alpha_{i n n}=\frac{(\xi / 8)(\operatorname{Re}-1000) \cdot \operatorname{Pr}}{1+12.7 \sqrt{(\xi / 8)}\left(\operatorname{Pr}^{2 / 3}-1\right)} \cdot \frac{\lambda_{s}}{d_{i n n}}
$$

where $\lambda_{s}$ is the thermal conductivity of single phase water or steam and $\xi$ Bhatti-Shah friction factor. For dualphase flows, the heat transfer coefficient considering both connective and nucleate boiling could be obtained by Eq. (5) [18].

$$
\alpha_{i n n}=\sqrt[3]{\alpha_{c o n v}^{3}+\alpha_{B}^{3}}
$$

where $\alpha_{c o n v}$ and $\alpha_{B}$ are the heat transfer coefficient of convective flow boiling and heat transfer coefficient of nucleate boiling respectively.

The properties of water or steam were calculated using the formulation proposed by Wagner [19]. The properties of the gas turbine exhaust gas were calculated by NASA computer programme CEA [20] based on the composition, pressure and temperature of the exhaust gas.

\subsubsection{Heat Balance}

The heat transfer $Q$ between the gas and water-steam flows in OTSG circuits is represented by Eq. (6)

$$
Q=W \cdot\left|h_{\text {in }}-h_{\text {out }}\right|
$$

where $h_{\text {in }}$ and $h_{\text {out }}$ are the inlet and outlet specific enthalpy of either the hot side or cold side of an OTSG circuit and $W$ is mass flow rate. The heat transfer in an OTSG section is driven by a logarithmic mean temperature difference (LMTD) [21] defined by Eq. (7):

$$
L M T D=\frac{\left(\Delta T_{I}-\Delta T_{I I}\right)}{\ln \left(\Delta T_{I} / \Delta T_{I I}\right)}
$$


where $\Delta T_{I}=T_{\text {hot,in }}-T_{\text {cold,out }}$, and $\Delta T_{I I}=T_{\text {hot,out }}-T_{\text {cold,in }}$. The heat transfer rate of any OTSG sections is represented by Eq. (8) [21]:

$$
Q=U \cdot A \cdot L M T D
$$

where $A$ is the heat transfer area and $U$ is the overall heat transfer coefficient.

\subsubsection{Once-through Steam Generator Efficiency}

The efficiency of an OTSG is defined by Eq. (9)

$$
\eta=\left(T_{1}-T_{8}\right) /\left(T_{1}-T_{a m b}\right)
$$

where $T_{1}$ is the OTSG inlet gas temperature, $T_{8}$ is the stack temperature, and $T_{a m b}$ is the ambient temperature.

\subsubsection{Heat Transfer Ratio}

The heat transfer ratio defined by Eq. (10) represents the ratio between the heat transfer of section ( $\mathrm{x}-\mathrm{y})$ and that of section $(\mathrm{u}-\mathrm{v})$, where the former is a subsection of the latter:

\subsubsection{Ratio of Heat Transfer Areas}

$$
C f_{x y / u v}=Q_{x y} / Q_{u v}
$$

Equation (11) defines the ratio between the heat transfer area of section $(\mathrm{x}-\mathrm{y})$ and that of section $(\mathrm{u}-\mathrm{v})$; the former is a subsection of the latter:

$$
C A_{x y / u v}=A_{x y} / A_{u v}
$$

\subsection{Design Point Performance Calculation of Parallel Dual-pressure OTSG}

\subsubsection{Input Parameters}

Figure 3 shows the simulation flowchart of a parallel dual-pressure OTSG at the DP where the following gas path input parameters are given:

- $\quad$ Gas inlet temperature: $T_{1}$

- Gas mass flow rate: $W_{\text {exh }}$

- Ambient temperature: $T_{\mathrm{amb}}$

- $\quad$ HP circuit steam temperature: $T_{a}$

- HP circuit steam pressure: $P_{a}$

- $\quad H P$ pinch point temperature difference: $P P_{H P}$

- $\quad$ HP feed water temperature: $T_{j}$ 
- $\quad$ LP circuit steam temperature: $T_{e}$

- $\quad$ LP circuit steam pressure: $P_{e}$

- $\quad$ LP pinch point temperature difference: $P P_{L P}$

- $\quad$ LP feed water temperature: $T_{h}$

- Heat transfer ratio of section (d-i) over (c-j): $C f_{d i / c j}$

- Heat transfer ratio of section (i-j) over $(\mathrm{c}-\mathrm{j}): C f_{i j / c j}$

\subsubsection{State Variables}

To quantify the heat transfer $\left(Q_{d m}, Q_{m n}\right.$, and $\left.Q_{n i}\right)$ within subsection (d-i) and obtain a DP solution, two iteration variables are selected, as defined by Eq. (10), as follows:

- Heat transfer ratio between section (d-m) and section (d-i): $C f_{d m / d i}$

- Heat transfer ratio between section (m-n) and section (d-i): $C f_{m n / d i}$

\subsubsection{Errors and Root Mean Square Error}

The heat transfer area is proportional to the length of the tube when the tube cross-section diameter is constant. Meanwhile, it is assumed that the tube length is proportional to the $\mathrm{X}$-axis in Fig. 2, so the heat transfer area is proportional to the $\mathrm{X}$-axis. It can be seen in Fig. 2 that points $\mathrm{d}$ and $\mathrm{e}, \mathrm{m}$ and $\mathrm{f}, \mathrm{n}$ and $\mathrm{g}$, and $\mathrm{i}$ and $\mathrm{h}$ have the same flow path locations on the X-axis, respectively. Therefore, $C A_{e f / e h}$ should equal to $C A_{d m / d i}$, and $C A_{f g / e h}$ should equal to $C A_{m n / d i}$. Thus, two errors are identified as follows:

- $\Delta Y_{1}=\left(C A_{e f / e h}-C A_{d m / d i}\right) / C A_{d m / d i}$

- $\Delta Y_{2}=\left(C A_{f g / e h}-C A_{m n / d i}\right) / C A_{m n / d i}$

The Root Mean Square (RMS) of the errors is defined by Eq. (12), required to be less than a threshold $\sigma(1 \mathrm{E}-05)$ as convergence criteria.

$$
R M S=\sqrt{\frac{1}{G} \sum_{k=1}^{G}\left(\Delta Y_{k}\right)^{2}}<\sigma
$$

where $G$ is the number of the errors; for DP calculations $G=2$. 


\subsubsection{Newton Raphson Method}

To satisfy the above convergence criteria, Newton Raphson (NR) iteration method [22] was used to search for an optimal solution of the variables $\left(C f_{d m / d i}\right.$ and $\left.C f_{m n / d i}\right)$ by Eq. (13) until the RMS of the errors defined by Eq. (12) is less than a threshold $\sigma$.

$$
X_{n+1}=X_{n}-f\left(X_{n}\right) / f^{\prime}\left(X_{n}\right)
$$

where $X$ is an iteraiton variable, $\mathrm{n}$ is the number of iterations, $f(\cdot)$ is the OTSG system function that represents an implicit functional relationship between the variables and errors, and $f^{\prime}(\cdot)$ is the function's derivative that could be obtained through the Jacobian matrix.

\subsubsection{Design Point Performance Calculation Algorithm}

Figure 3 shows the simulation flowchart for a parallel dual-pressure OTSG DP performance simulation. The calculation for each section of the OTSG and the iterative process are explained as follows:

(1) The initial values of the two variables $C f_{d m / d i}$ and $C f_{m n / d i}$ are guessed based on experience. Their initial values have influence on the convergence of the iterations. Trial and errors may be used to find their best values. In this study, 0.35 is chosen as the initial value for both variables.

(2) Section ( $a-b-c-d)$ and Section (1-2-3-4)

$T_{b}=T_{c}$ is the saturated temperature in the HP circuit that can be calculated once $P_{a}$ is given. Therefore, $T_{3}$ is determined by Eq. (14):

$$
T_{3}=T_{c}+P P_{H P}
$$

Among the points indicated in Fig. 2, the temperature at positions 1, 3, a, and c are known. Based on the heat balance between the hot side (1-3) and cold side (a-c), the HP circuit mass flow rate $W_{H P}$ can be calculated by Eq. (6). Therefore, $T_{2}$ can be obtained based on the heat balance between the hot side (1-2) and cold side (a-

b). $Q_{c j}$ can be decided by $W_{H P}, T_{c}$, and $T_{j}$. Therefore, $Q_{c d}$ can be calculated by Eq. (15).

$$
Q_{c d}=C f_{c d / c j} \cdot Q_{c j}=\left(1-C f_{d i / c j}-C f_{i j / c j}\right) \cdot Q_{c j}
$$

As $W_{H P}, T_{c}$, and $Q_{c d}$ have already been determined, $T_{d}$ can be calculated by Eq. (6) at the HP water circuit (c-

d). Based on the heat balance between sections (c-d) and (3-4), $T_{4}$ can be determined by Eq. (6).

(3) Section $(d-m-n-i)$, Section $(e-f-g-h)$ and Section (4-5-6-7) 
$C f_{d i / c j}$ is known as an input parameter and $Q_{d i}$ can be obtained by Eq. (10). Therefore, $T_{i}$ can be obtained based on $Q_{d i}, W_{H P}$, and $T_{d}$.

$T_{f}=T_{g}$ is the saturated temperature in the LP circuit that can be obtained once $P_{e}$ is given. Therefore $T_{6}$ can be obtained by Eq. (16).

$$
T_{6}=T_{g}+P P_{L P}
$$

Section $(\mathrm{d}-\mathrm{i})$ is divided into three sections, $(\mathrm{d}-\mathrm{m}),(\mathrm{m}-\mathrm{n})$ and $(\mathrm{n}-\mathrm{i})$. The variables $C f_{d m / d i}$ and $C f_{m n / d i}$ are guessed in iterations where $Q_{d m}, Q_{m n}$ and $Q_{n i}$ can be calculated respectively by Eq. (10) and $Q_{d n}$, can be calculated by Eq. (17).

$$
Q_{d n}=\left(C f_{d m / d i}+C f_{m n / d i}\right) \cdot Q_{d i}
$$

Therefore, $T_{m}$ can be obtained based on $Q_{d m}, W_{H P}$ and $T_{d}$. Similarly, $T_{n}$ can be calculated. As the temperature at points 4, 6, e, and g are known, the heat transfer rate at the cold side between (e-g) and (d-n) and at the hot side (4-6) can be obtained based on heat balance shown by Eq. (18).

$$
W_{L P} \cdot\left(h_{e}-h_{g}\right)=Q_{e g}=Q_{46}-Q_{d n}
$$

Therefore, the LP circuit mass flow rate $W_{L P}$ can be determined, and this is then used to derive the heat transfer rates $Q_{e f}, Q_{f g}, Q_{g h}$ and $Q_{e h}$ by Eq. (6).

$T_{5}$ can be calculated via the heat balance between the hot section (4-5) and cold sections ( $\left.d-m\right)$ and (e-f) by Eq. (19) combined with Eq. (6). Similarly, $T_{7}$ can be calculated based on the heat balance between the hot section (6-7) and cold sections ( $\mathrm{g}-\mathrm{h})$ and (n-i) by Eqs. (20) and (6).

$$
\begin{aligned}
& Q_{e f}+Q_{d m}=Q_{45}=W_{e x h} \cdot\left(h_{4}-h_{5}\right) \\
& Q_{g h}+Q_{n i}=Q_{67}=W_{e x h} \cdot\left(h_{6}-h_{7}\right)
\end{aligned}
$$

(4) Section (i-j) and Section (7-8)

As $C f_{i j / c j}$ is known, $Q_{i j}$ can be obtained based on $C f_{i j / c j}$ and $Q_{c j}$ by Eq. (10). Hence, the OTSG stack temperature $T_{8}$ can be obtain by Eq. (21).

$$
Q_{i j}=Q_{78}=W_{e x h} \cdot\left(h_{7}-h_{8}\right)
$$

(5) Heat Transfer Areas 
From the results of the above calculations, the DP performance of the OTSG is obtained provisionally, and LMTD and the heat transfer areas for each section $\left(A_{a b}, A_{b c}, A_{c d}, A_{d m}, A_{m n}, A_{n i}, A_{i j}, A_{e f}, A_{f g}\right.$, and $\left.A_{g h}\right)$ can be calculated based on the continuation of energy by Eq. (8). Therefore, the heat transfer areas of the whole HP and LP steam circuits can be calculated by Eqs. (22) and (23):

$$
\begin{gathered}
A_{a j}=A_{a b}+A_{b c}+A_{c d}+A_{d m}+A_{m n}+A_{n i}+A_{i j} \\
A_{e h}=A_{e f}+A_{f g}+A_{g h}
\end{gathered}
$$

\section{(6) Iterations and Convergence}

$C A_{e f / e h}$ can be calculated by Eq. (24). Similarly, $C A_{f g / e h} C A_{d m / d i}$, and $C A_{m n / d i}$ can be determined.

$$
C A_{e f / e h}=A_{e f} / A_{e h}
$$

Therefore, $\Delta Y_{1}$ and $\Delta Y_{2}$ are calculated and the RMS can be obtained by Eq. (12). If the RMS is less than the threshold, the iteration will be terminated and the OTSG efficiency will be obtained by Eq. (9). Meanwhile, the non-dimensional steam flow capacity at OTSG outlets can be obtained. If the convergence criteria are not satisfied, the two iteration variables will be updated by Eq. (13) and the calculations will be repeated from Step (2) using the Newton-Raphson method.

The above calculation process may be used for the preliminary design of a new OTSG where the heat transfer ratios $C f_{d i / c j}$ and $C f_{i j / c j}$ are specified and the heat transfer areas and OTSG performance are calculated.

\subsection{Off-design Performance Calculation Algorithm}

\subsubsection{Input Parameters}

The OD performance of an OTSG refers to an existing OTSG operating at different ambient and operating conditions. The input parameters for the OTSG at OD operating conditions are as follows:

- Gas inlet temperature: $T_{1}$

- Gas mass flow rate: $W_{\text {exh }}$

- Steam Turbine Erosion Factor: $E F$

- Ambient temperature: $T_{a m b}$

- HP feed water temperature: $T_{j}$

- $\quad$ LP feed water temperature: $T_{h}$ 


\subsubsection{Iteration Variables}

The following six parameters in an OTSG system are selected as variables that determine the status of the OTSG:

- $\quad$ HP circuit mass flow rate: $W_{H P}$

- $\quad$ LP circuit mass flow rate: $W_{L P}$

- Heat transfer ratio of section $\mathrm{d}-\mathrm{i}$ over $\mathrm{c}-\mathrm{j}: C f_{d i / c j}$

- Heat transfer ratio of section $\mathrm{i}-\mathrm{j}$ over $\mathrm{c}-\mathrm{j}: C f_{i j / c j}$

- Heat transfer ratio of section d-m over d-i: $C f_{d m / d i}$

- Heat transfer ratio of section $\mathrm{m}-\mathrm{n}$ over $\mathrm{d}-\mathrm{i}: C f_{m n / d i}$

\subsubsection{Iteration Errors}

As mentioned already, $A_{a d}, A_{d i}, A_{i j}$, and $A_{e h}$ are constant under all conditions and they are used to set up OD convergence criteria. In addition, the two DP convergence criteria also need to be satisfied under OD conditions. Therefore, the following six iteration errors are identified:

- $\Delta Y_{1}=\left(A_{a d \_o D}-A_{a d}\right) / A_{a d}$

- $\quad \Delta Y_{2}=\left(A_{d i_{-} O D}-A_{d i}\right) / A_{d i}$

- $\Delta Y_{3}=\left(A_{i j \_O D}-A_{i j}\right) / A_{i j}$

- $\Delta Y_{4}=\left(A_{e h \_O D}-A_{e h}\right) / A_{e h}$

- $\Delta Y_{5}=\left(C A_{e f / e h}-C A_{d m / d i}\right) / C A_{d m / d i}$

- $\Delta Y_{6}=\left(C A_{f g / e h}-C A_{m n / d i}\right) / C A_{m n / d i}$

\subsubsection{Off-design Performance Calculation Algorithm}

Figure 4 illustrates the calculation flowchart of the OD performance calculation of a parallel dual-pressure OTSG with detailed description given as follows:

(1) The initial values of the six variables $W_{H P}, W_{L P}, C f_{d i / c j}, C f_{i j / c j}, C f_{d m / d i}$, and $C f_{m n / d i}$ take their values at DP point to start the calculation.

(2) Sections $(a-b-c-d)$ and $(1-2-3-4)$

At a changing OD condition, the desired HP steam temperature $T_{a}$ is determined by Eq. (25) where the value of the controlled temperature " $484^{\circ} \mathrm{C}$ " is case specific and may be different for different power plants. If such 
a desired value of $T_{a}$ is not satisfied, the feed water mass flow rate will be adjusted by a feedback control to obtain such $T_{a}$.

$$
\begin{cases}T_{a}=T_{1}-14 & T_{1} \leq 500^{\circ} \mathrm{C} \\ T_{a}=484 & T_{1}>500^{\circ} \mathrm{C}\end{cases}
$$

If an OTSG inlet gas flow rate drops due to the reduction of upstream gas turbine load, less steam will be generated by the OTSG, and consequently the steam pressure has to respond for keeping the same steam flow capacity represented by Eq. (26) [23]. This refers to sliding control that is widely used for steam cycle OD operation [24].

$$
\frac{W \cdot \sqrt{T}}{P}=\frac{W_{D P} \cdot \sqrt{T_{D P}}}{P_{D P}} \cdot E F
$$

where $W$ is the steam mass flow rate, $T$ the steam temperature, $P$ the steam pressure, and $E F$ the erosion factor of the downstream steam turbine [25]. The increase of $E F$ represents steam turbine erosion regarded as degradation.

The HP steam pressure $P_{a}$ can be determined, if $T_{a}$ and $W_{H P}$ are available for Eq. (26). Once the steam pressure is known, the saturation temperature at points $b$, and $c$ can be calculated. Based on the heat balance between the hot side (1-2) and cold side (a-b), $T_{2}$ can be obtained by Eq. (6). Following the same procedure, $T_{3}$ can be determined based on the heat balance between the hot side (2-3) and cold side $(b-c)$.

Since the OTSG inlet feed water temperature is given, the $Q_{c j}$ needed for the HP economizer can be calculated by $T_{c}, T_{j}$, and $W_{H P}$. Hence, the $Q_{c d}$ can be obtained by Eq. (15). Then, $T_{d}$, and $T_{4}$ are determined in the same way as that in the DP performance calculation.

(3) Sections $(d-m-n-i),(e-f-g-h)$ and (4-5-6-7)

$Q_{d i}$ and $T_{i}$ can be obtained in the same way as that in DP calculation. The LP steam temperature $T_{e}$ is obtained by setting the constant difference between $T_{4}$ and $T_{e}$. Then $P_{e}$ can be decided by Eq. (26). Correspondingly, saturation temperature $T_{f}$ and $T_{g}$ can be easily obtained. Based on the known temperature (i.e. $T_{e}, T_{f}, T_{g}$, and $T_{h}$ ) and the guessed value of $W_{L P}$, the value of $Q_{e f}, Q_{f g}$, and $Q_{g h}$ can be determined by Eq. (6). Based on the guessed $C f_{d m / d i}$ and $C f_{m n / d i}, Q_{d m}, Q_{m n}, Q_{n i}, T_{m}$ and $T_{n}$ are obtained. $T_{5}$ can be calculated based on Eq. (19). Similarly, $T_{6}$ is obtained via the heat balance between the hot section (5-6) and cold sections $(\mathrm{f}-\mathrm{g})$ and $(\mathrm{m}-\mathrm{n})$. In addition, $T_{7}$ can be obtained by Eq. (20).

(4) Sections $(i-j)$ and (7-8) 
$Q_{i j}$ is obtained by using $Q_{c j}$ and guessed $C f_{i j / c j}$. Then, $T_{8}$ can be calculated by Eq. (21).

(5) Heat Transfer Areas

At the end of the above calculations, the heat transfer areas (i.e. $A_{\text {ad_OD }}, A_{\text {di_ } O D}, A_{\text {ij_OD }}, A_{\text {eh_OD }}$ ), and the ratios of heat transfer areas (i.e. $C A_{e f / e h}, C A_{d m / d i}, C A_{f g / e h}$, and $C A_{m n / d i}$ ) can be calculated.

(6) Convergence Criteria and Iterations

Following the above calculations, the six OD errors $\Delta Y_{k}$ and the corresponding RMS can be calculated by Eq. (12). If the RMS is less than the threshold, the OD calculation finishes and the OTSG efficiency will be obtained by Eq. (9). Otherwise, the six iteration variables are updated by Eq. (13) and the calculation will be repeated from Step (2) following the Newton Raphson method until convergence is achieved.

\subsubsection{Average Prediction Error}

To assess the quality of the final solutions, an average prediction error $\bar{\gamma}_{i}$ for each measurement parameter at multiple OD points is defined by Eq. (27).

$$
\bar{\gamma}_{i}=\frac{1}{N} \sum_{j=1}^{N}\left|\frac{\bar{Z}_{i}-Z_{i}}{\bar{Z}_{i}}\right| \times 100 \%
$$

where $N$ is the number of OD points, $\bar{Z}_{i}$ is measured parameter, and $Z_{i}$ is simulated value of the same parameter.

\subsection{Overview of the Method}

For DP performance calculation, two variables $C f_{\mathrm{dm} / \mathrm{di}}$ and $C f_{m n / n i}$ are identified to determine the DP performance of the OTSG and two errors related to the two ratio of heat transfer areas. For OD performance calculations, six variables $W_{H P}, W_{L P}, C f_{d i / c j}, C f_{i j / c j}, C f_{d m / d i}$, and $C f_{m n / d i}$ are identified to determine the OD performance of the OTSG and six errors related to the consistency of heat transfer areas of circuit sections $(\mathrm{a}-\mathrm{d}),(\mathrm{d}-$ i), (i-j) and (e-h), and two ratio of heat transfer areas. Newton Raphson algorithm is used to reduce the errors and achieve the converged solutions of the DP and OD performance calculations.

\section{Application and Analysis}

The introduced performance simulation method has been applied to an OTSG installed in a CCGT power plant at Manx Utilities, Isle of Man in the United Kingdom. Some key performance data of the plant are showed in Table 1 [12],[26]. The power plant has General Electric LM2500+ aero-derivative GT engine as the prime mover providing 
exhaust gas to the OTSG for generating high pressure and high temperature steam driving a steam turbine for electricity generation.

\subsection{Once-through Steam Generator and Measurement}

The parallel dual-pressure OTSG manufactured by Innovative Steam Technologies (IST) is shown in Fig. 1 [12]. Table 1 shows relevant data used as input for the OTSG DP performance calculation.

\subsection{Design Point Performance Calculation and Validation}

The OTSG DP performance was calculated following the flowchart showed in Fig. 3. During the DP calculations, the two variables $\left(C f_{d m / d i}\right.$ and $\left.C f_{m n / d i}\right)$ are searched by Newton Raphson method to reduce the RMS error defined by Eq. (12). Table 2 shows the obtained simulation results of the DP performance calculation for the five measurement parameters compared with the data provided by IST and the plant operator [12],[26],[27]. The relative errors shown in Table 2 demonstrate that all the prediction errors are quite small, with the maximum error on $T_{8}$ being less than $0.8 \%$. It indicates that the DP simulation model and the results are satisfactory. The obtained values of the two variables are also showed in Tables 3 .

\subsection{Off-design Performance Simulation and Validation}

For the OD performance calculations, the values of input parameters listed in Section 2.4.1 are given. Due to confidentiality reasons, only the ranges of the OD input parameters are given in Table 4.

The OD performance was calculated following the flowchart showed in Fig. 4 where a solution of six state variables is searched by Newton Raphson method in order to satisfy the convergence criteria shown in Eq. (12). By satisfying the convergence criteria, the calculated total heat transfer areas $A_{a d}, A_{d i}, A_{i j}$, and $A_{e h}$ are kept unchanged at OD operating conditions, although the internal boundaries between the economizer, evaporator, and superheater in both the HP and LP circuits may change.

In this study, 292 sets of OTSG measurements were chosen from three-day steady state OD operations of the plant in August 2017 for the model validation, where the gas flow rate $W_{\text {exh }}$, exhaust gas temperature $T_{1}$, ambient temperature $T_{a m b}$, and feed water temperature vary during the operations. $P_{\mathrm{a}}$ and $P_{\mathrm{e}}$ are determined by Eq. (26) when mass flow rate and steam temperature are available. The desired HP steam temperature are kept by adjusting $W_{\mathrm{HP}}$ and $W_{\mathrm{LP}} . T_{8}$ and $T_{e}$ are determined for different $W_{\mathrm{HP}}$ and $W_{\mathrm{LP}}$ values during $\mathrm{OD}$ calculations. As the result of the OD 
performance calculations, the satisfactory consistency between the test data and the simulated results of $W_{\mathrm{HP}}, W_{\mathrm{LP}}$, $P_{\mathrm{a}}, P_{\mathrm{e}}, T_{8}$, and $T_{e}$ are demonstrated in Figs. 5-7. The maximum average error defined by Eq. (27) for individual parameters is less than $1.5 \%$ as shown in Fig. 8 demonstrating good prediction accuracies.

\subsection{Impact of Gas Turbine Power Setting and Steam Turbine Erosions}

\subsubsection{Impact of Gas Turbine Power Setting}

To illustrate the impact of power plant operating conditions on the performance of the OTSG, changing exhaust gas conditions indicated by dropping the prime mover (i.e. a gas turbine) power output is simulated by Cranfield's gas turbine performance simulation software PYTHIA Error! Reference source not found.. Meanwhile, the gas turbine exhaust conditions are applied to the input of the OTSG to assess the changes of OTSG performance at OD conditions.

Figure 9 shows the impact of gas turbine power drop on exhaust gas temperature and exhaust gas mass flow rate simulated by the gas turbine performance model. It is assumed that the OTSG feed water condition and steam turbine flow capacity maintain the same. It can be seen that the steam properties such as steam mass flow rate, total pressure and total temperature decrease with the reduction of gas turbine power illustrated in Figs. 10 (a) - (c) where the gas turbine power changes from $32 \mathrm{MW}$ (DP condition) to $22 \mathrm{MW}$. Figure 10 (d) shows the decreasing of OTSG stack temperature $T_{8}$ and OTSG efficiency $\eta$ with the reduction of gas turbine power setting. In addition, the moving boundary between the economizer, evaporator and superheater in the OTSG demonstrated by the variations of the heat transfer areas $A_{a b}, A_{b c}, A_{c j}, A_{e f}, A_{f g}$ and $A_{g h}$ are shown in Figs. 10 (e) - (f) respectively while the total heat transfer areas $A_{a j}$ and $A_{e h}$ are unchanged.

\subsubsection{Impact of Steam Turbine Erosion}

Erosion is a degradation phenomenon in a steam turbine, and it increases steam turbine flow capacity. Such an increase is represented by the change of Erosion factor $E F$. It is assumed that the exhaust gas conditions maintain the same as GT DP, so the HP steam temperature is maintained at its DP value. Three cases are demonstrated in Fig. 11 that covers (1) HP part of steam turbine erosion only, (2) LP part of steam turbine erosion only, and (3) both the HP and LP parts of steam turbine erosion. No erosion is represented by the erosion factor being 1.0 in Fig. 11.

When steam turbine erosion happens, OTSG has to reach a new equilibrium condition resulting in an increase of steam mass flow rate. Due to the sliding control shown by Eq. (25) the steam pressure has to drop in order to satisfy the increasing steam flow capacity. The reduction of steam pressure is shown in Fig. 11 (a) for all three cases. Figures 
11 (b) - (c) show the HP erosion would lead to an increase of $W_{H P}$ and a decrease of $W_{L P}$ and the LP erosion will result in an increase of $W_{L P}$ and a reduction of $W_{M P}$. Meanwhile, the change of $W_{H P}$ and $W_{L P}$ for third cases is the combined effect of HP and LP steam turbine erosions. Figure 11 (d) shows the LP steam temerpature $T_{e}$ is droping for all three cases because the decrease of HP steam pressure increases the heat transfer in evaporator and superheater, and therefore results in a reduciton in $T_{4}$. It can be seen in Fig. 11 (e) that the OTSG stack temperatures decrease with the increase of erosion factor in all three cases when the OTSG inlet gas conditions are kept unchanged, which indicates an increasing OTSG efficiency in Fig. 11 (f). This means that the erosion results in decreasing steam pressures and therefore increase the heat transfer and therefore improve the efficiency of the OTSG.

\section{Conclusions}

In this study, a novel algorithm for the DP and OD thermodynamic performance simulation of a parallel dualpressure OTSG is presented. It considers dual pressure parallel circuits and moving boundaries between the economizer, evaporator, and superheater of both the HP and LP steam circuits. The new method has been applied to the simulation and prediction of the performance of an OTSG installed in a CCGT power plant located at MU, Isle of Man, United Kingdom. A comparison between the predictions and the OTSG field data show that the proposed method offers good prediction accuracy in the OTSG performance simulations with the maximum average prediction error being less than $1.5 \%$. The simulated results also demonstrate the impact of the gas turbine prime mover on the OTSG performance and the floating boundaries between the economizer, evaporator and superheater of both the OTSG HP and LP circuits at part load operating conditions. Moreover, the obtained results show that the downstream steam turbine erosion by $10 \%$ would increase the OTSG efficiency by $0.35-0.8 \%$. The proposed simulation method can simulate the performance of new or existing dual pressure OTSG systems with parallel circuit configurations at both DP and OD operating conditions.

\section{References}

[1] Carazas, F.J.G., Salazar, C.H. and Souza, G.F.M.D., 2011, “Availability analysis of heat recovery steam generators used in thermal power plants", Energy, 36(6), pp.3855-3870.

[2] Ahmadi, P. and Dincer, I., 2011, "Thermodynamic analysis and thermoeconomic optimization of a dual pressure combined cycle power plant with a supplementary firing unit”, Energy Conversion and Management, 52(5), pp.22962308. 
[3] Nadir, M. and Ghenaiet, A., 2015, “Thermodynamic optimization of several (heat recovery steam generator) HRSG configurations for a range of exhaust gas temperatures”, Energy, 86, pp.685-695.

[4] Bassily, A.M., 2007, "Modeling, numerical optimization, and irreversibility reduction of a triple-pressure reheat combined cycle", Energy, 32(5), pp.778-794.

[5] Plis, M. and Rusinowski, H., 2018, “A mathematical model of an existing gas-steam combined heat and power plant for thermal diagnostic systems”, Energy, 156, pp.606-619.

[6] Oko, C.O.C. and Njoku, I.H., 2017, "Performance analysis of an integrated gas-, steam-and organic fluid-cycle thermal power plant”, Energy, 122, pp.431-443.

[7] Bayless, P.D., 1979, “A performance model for a helically coiled once-through steam generator tube”, Master's thesis, Massachusetts Institute of Technology.

[8] Yoon, J., Kim, J.P., Kim, H.Y., Lee, D.J. and Chang, M.H., 2000, "Development of a computer code, ONCESG, for the thermal-hydraulic design of a once-through steam generator", Journal of Nuclear Science and Technology, 37(5), pp.445454.

[9] Dumont, M.N. and Heyen, G., 2004, "Mathematical modeling and design of an advanced once-through heat recovery steam generator", Computers \& Chemical Engineering, 28(5), pp.651-660.

[10] Ngoma, G.D., Sadiki, A. and Wamkeue, R., 2003, "Efficient approach in modeling and simulation of dual pressure oncethrough heat recovery steam generator", Proceeding Power and Energy Systems, 379, pp. 218-223.

[11] Hamid, E., Newby, M., \& Pilidis, P., 2011, "Performance Modeling of Unfired Steam Cycle Using Single and Dual Pressure Once-Through Steam Generator", ASME Turbo Expo 2011, American Society of Mechanical Engineers.

[12] Manx Utilities., 2017, “Welcome to Pulrose Power Station”, Accessed https://www.manxutilities.im/media/1138/welcome-to-pulrose-power-station.pdf in 2017.

[13] Klaus, G.S., 2010, “VDI Heat Atlas: Heat Transfer to Finned Tubes”, Duisburg, Germany: Springer-Verlag.

[14] Hans, M.S., 2010, “VDI Heat Atlas: Fouling of Heat Exchanger Surfaces”, Stuttgart, Germany: Springer-Verlag.

[15] Belmiloudi, A., 2011, "Heat transfer-theoretical analysis, experimental investigations and industrial systems", Vienna: InTech (Open access Publisher).

[16] Dechamps, P.J., 1994, June, "Modeling the transient behavior of combined cycle plants", ASME 1994 International Gas Turbine and Aeroengine Congress and Exposition (pp.V004T10A001-V004T10A001), Hague, Netherlands.

[17] Gnielinski, V., 1983, "Forced convection in ducts", Schlünder EU, Bell KJ et al. (eds) HEDH-heat exchanger design handbook. Washington, DC: Hemisphere \& VDI.

[18] Matthias, K., and Yasushi, S., 2010, "VDI Heat Atlas: Saturated Flow Boiling”, Karlsruhe, Germany, Springer-Verlag.

[19] Wagner, W. K., 1998, “Properties of water and steam/IAPWS-IF97”, Berlin, Germany: Springer-Verlag. 
[20] NASA, CEA, Access 2015. "NASA computer program for calculating of the Chemical Equilibrium with Application", NASA Glenn Research Center, Cleveland, $\mathrm{OH}$.

[21] Shah, R.K. and Sekulic, D.P., 2003, “Fundamentals of heat exchanger design”, New Jersey, Canada. John Wiley \& Sons.

[22] Li, Y.G., 2015, “Aero gas turbine flight performance estimation using engine gas path measurements", Journal of Propulsion and Power, 31(3), pp, 851-860.

[23] Cooke, D. H., 1985, “On prediction of off-design multistage turbine pressures by Stodola's ellipse”, Journal of engineering for gas turbines and power, 107(3), 596-606.

[24] Kehlhofer, R., Hannemann, F., Rukes, B., \& Stirnimann, F., 2009, “Combined-cycle gas \& steam turbine power plants”, Pennwell Books.

[25] Lakshminarasimha, A.N., Boyce, M.P. and Meher-Homji, C.B., 1994, "Modeling and analysis of gas turbine performance deterioration", Journal of engineering for gas turbines and power, 116(1), pp.46-52.

[26] Innovative Steam Technologies, 2015, “IST-2015-Manx-Electricity-Authority”, Accessed https://otsg.com/istuploads/2015/04/2015-Manx-Electricity-Authority.pdf in 2017.

[27] Emad, H., 2011, "Performance simulation of combined cycle gas \& steam turbine power plant", PhD’s thesis, Cranfield University.

[28] Li, Y.G. and Singh, R., 2005, “An advanced gas turbine gas path diagnostic system-PYTHIA”. In XVII International Symposium on Air Breathing Engines, Munich, Germany, Paper No. ISABE-2005-1284. 


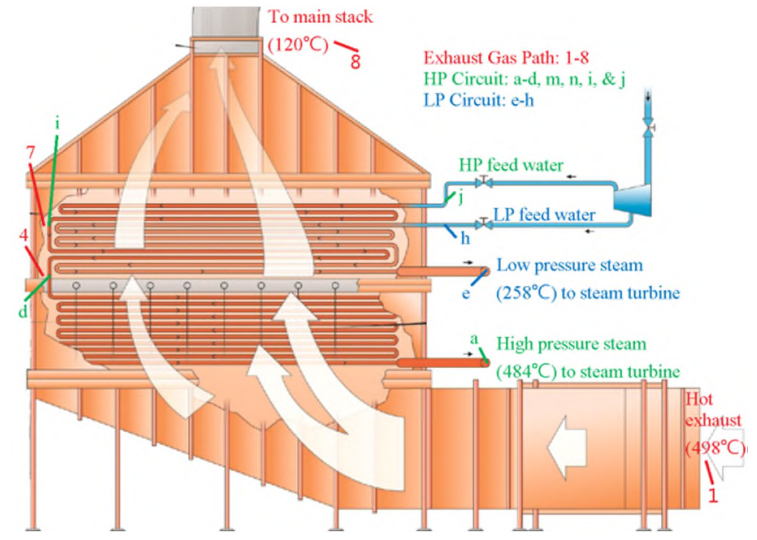

Fig. 1 Schematic of Once-through Steam Generator (OTSG) [12].

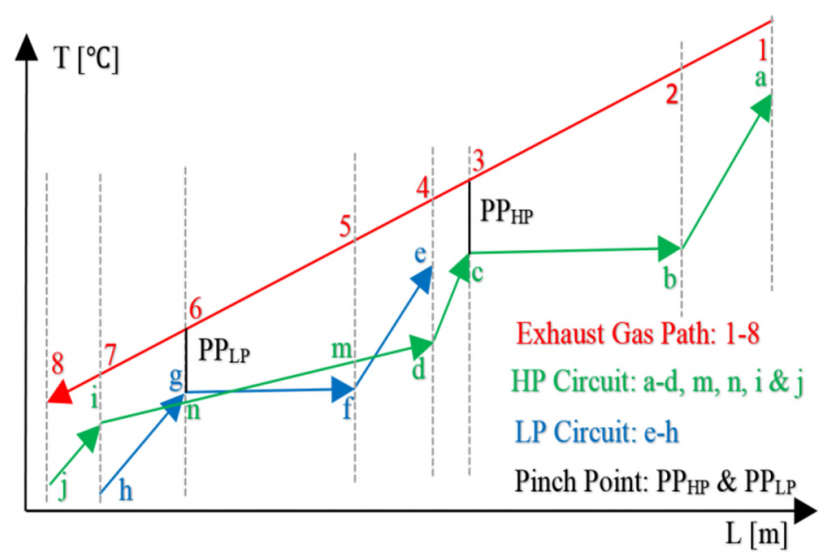

Fig. 2 OTSG Temperature Profiles along OTSG Gas Path. 


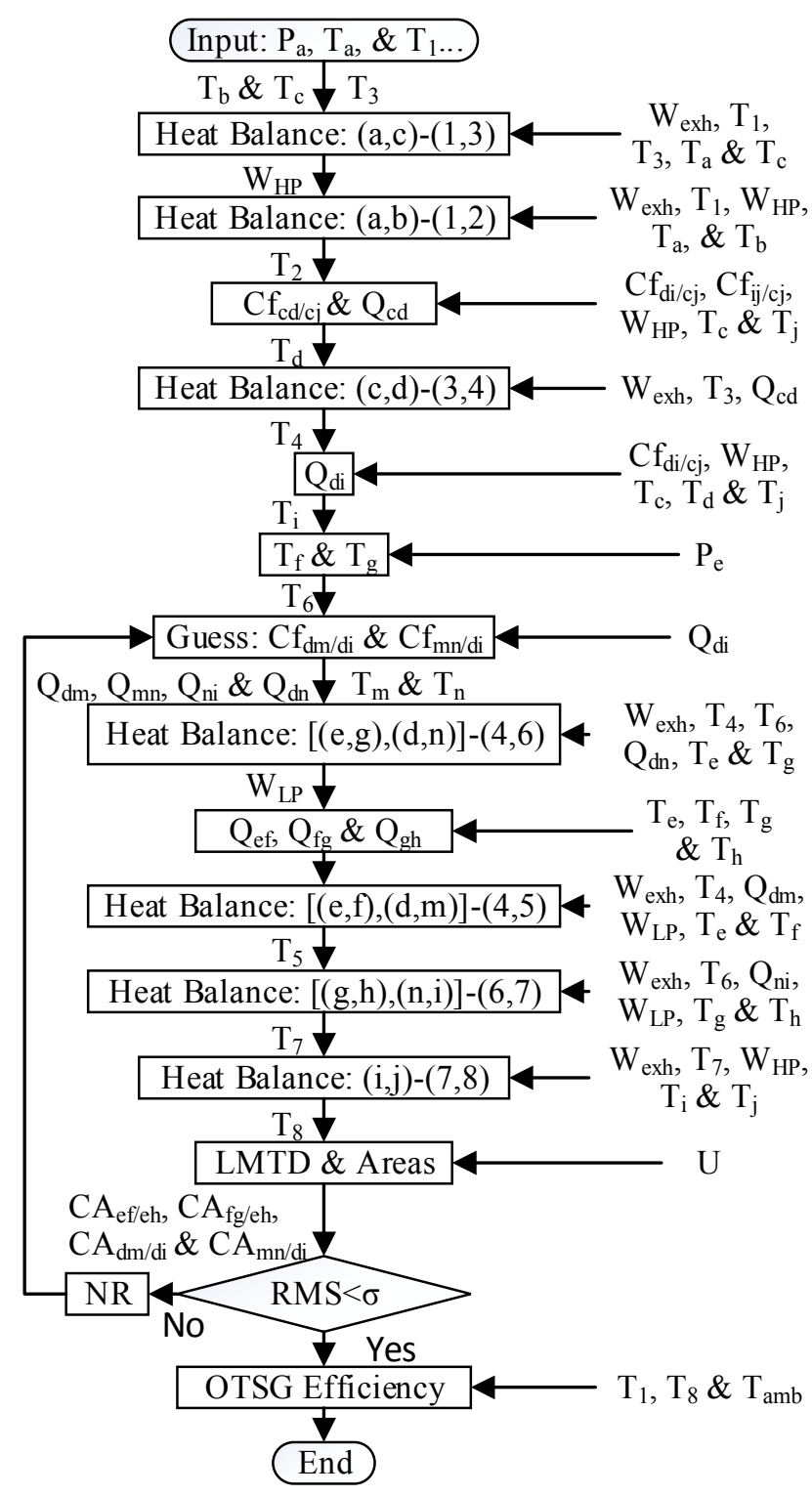

Fig. 3 OTSG Design Point (DP) Performance Calculation. 


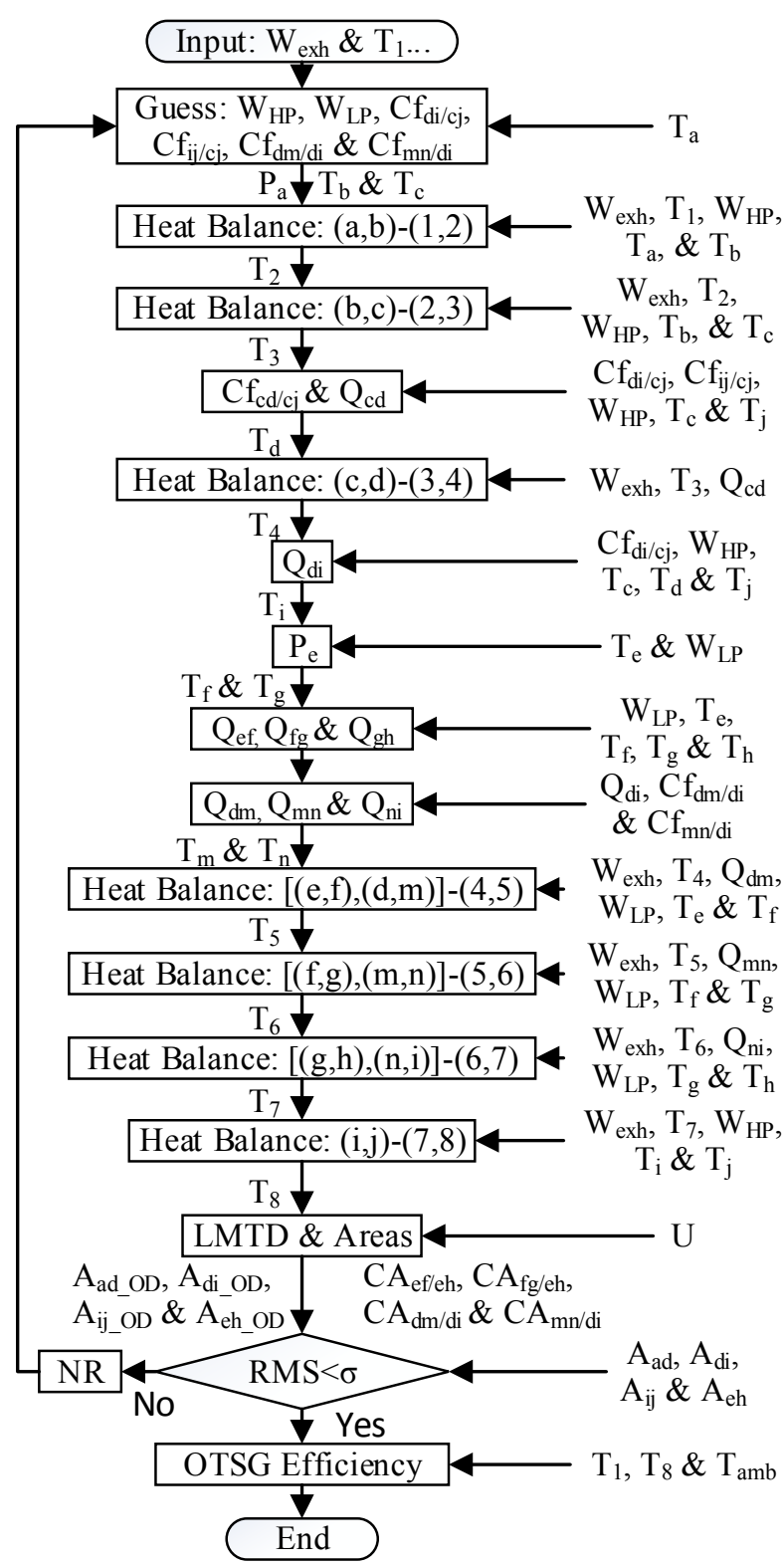

Fig. 4 OTSG Off-Design (OD) Performance Calculation. 

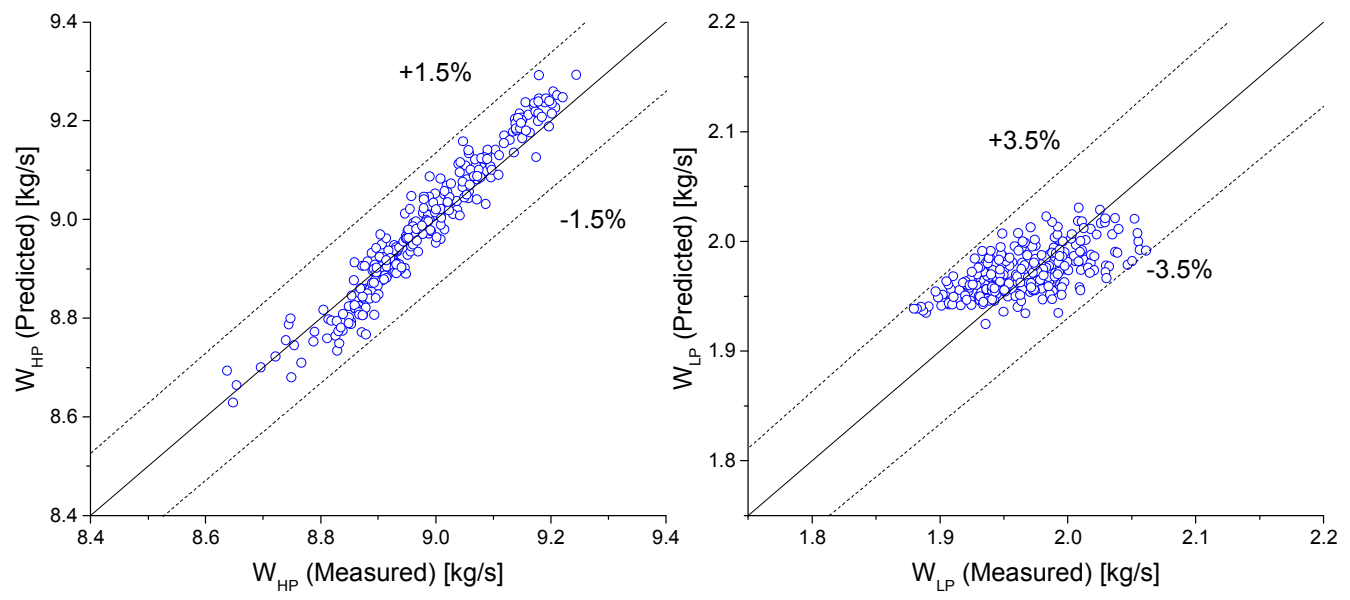

Fig. 5 Comparison between Measured and Predicted Results $\left(W_{H P}\right.$ and $\left.W_{L P}\right)$.
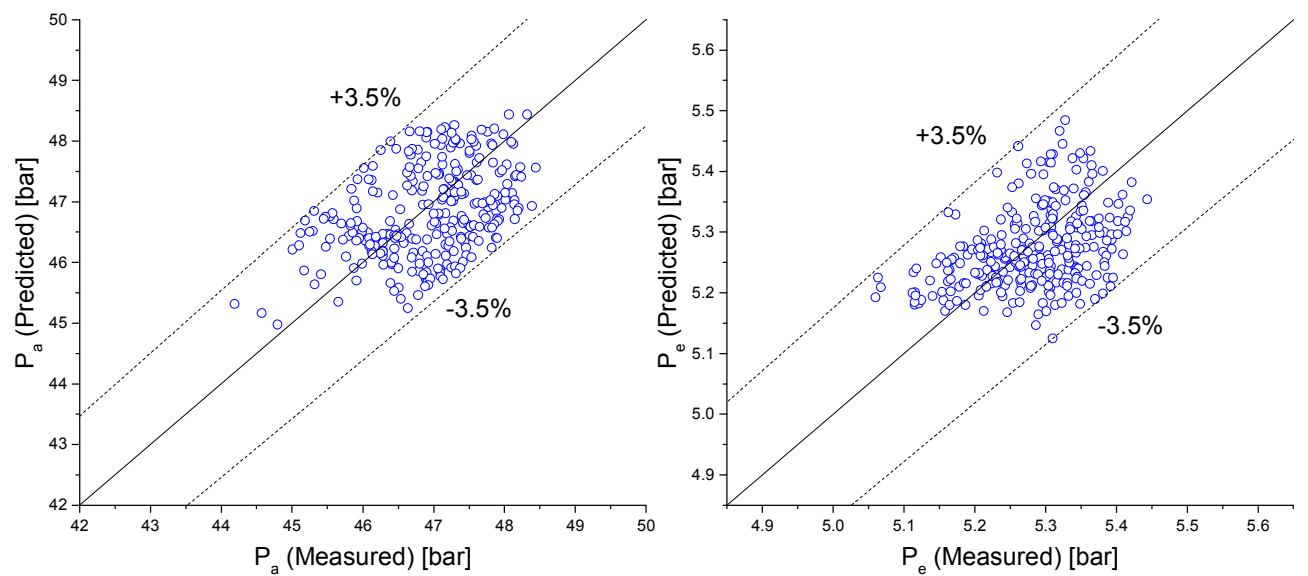

Fig. 6 Comparison between Measured and Predicted Results $\left(P_{a}\right.$ and $\left.P_{e}\right)$.
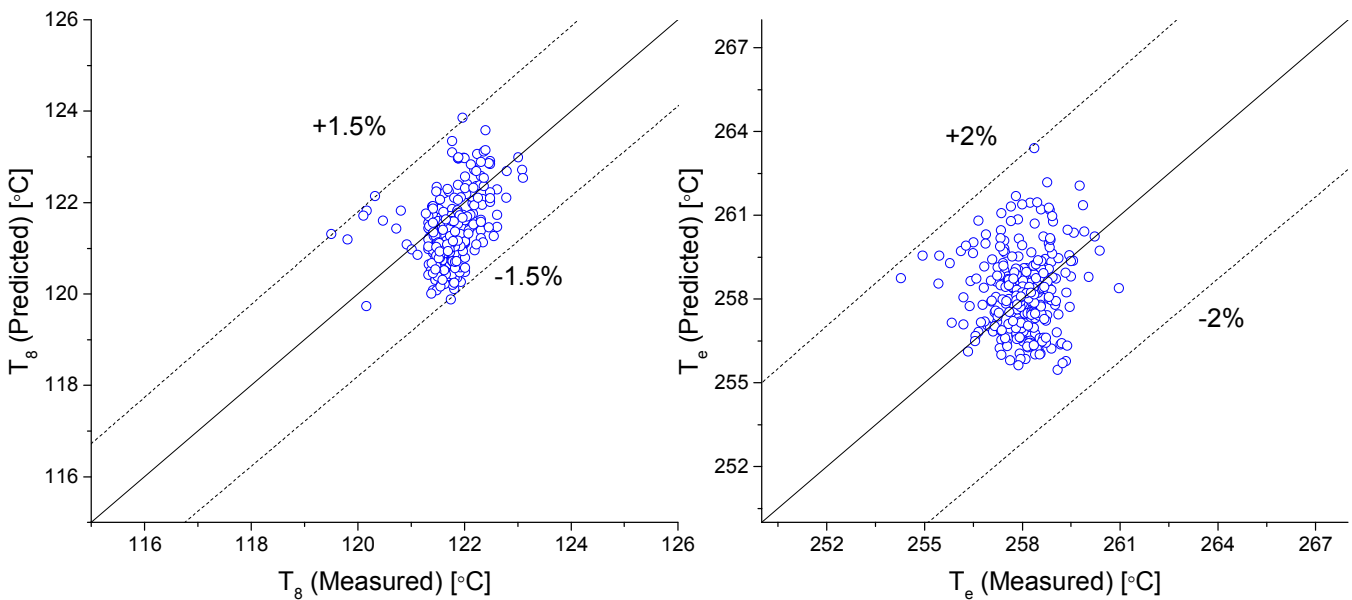

Fig. 7 Comparison between Measured and Predicted Results $\left(T_{8}\right.$ and $\left.T_{e}\right)$. 


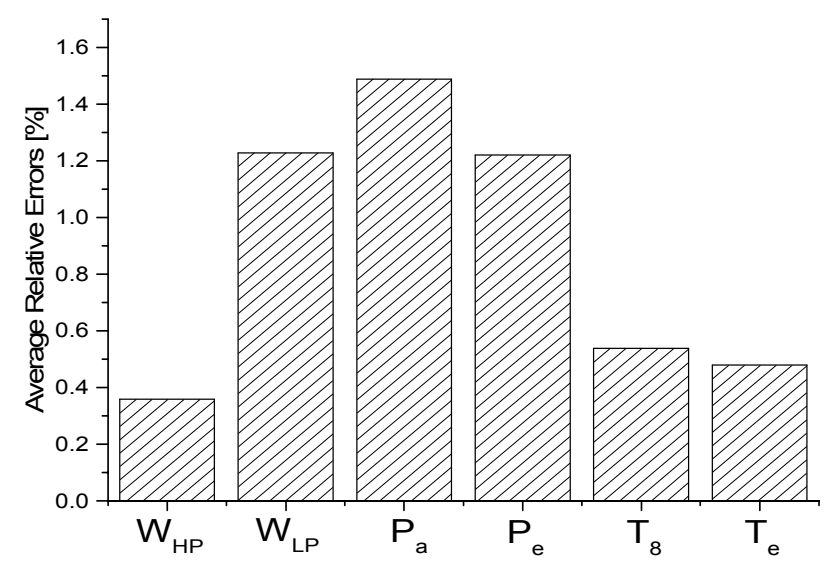

Fig. 8 Average Relative Errors of 292 Test Points.

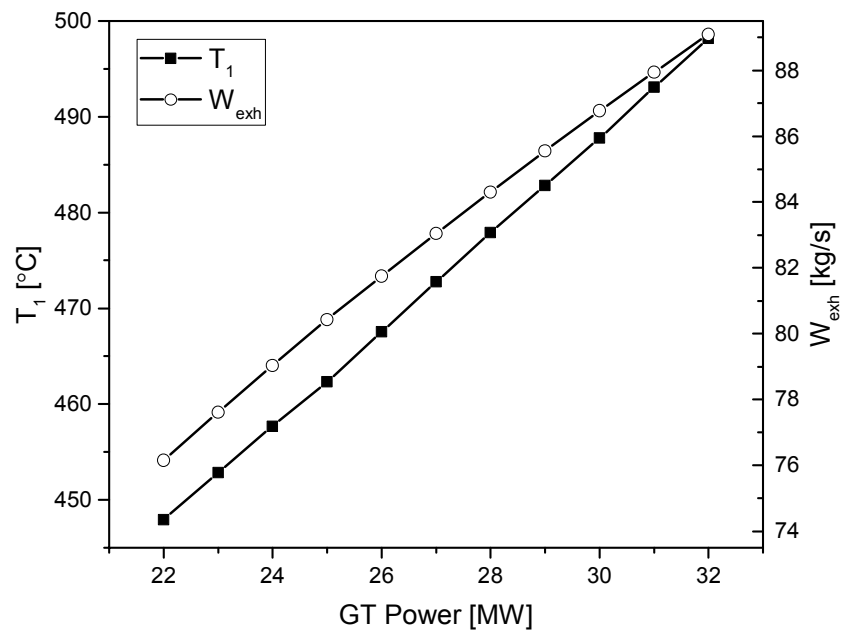

Fig. 9 Effect of Gas Turbine (GT) Power on Exhaust Gas $T_{1}$ and $W_{\text {exh }}$. 


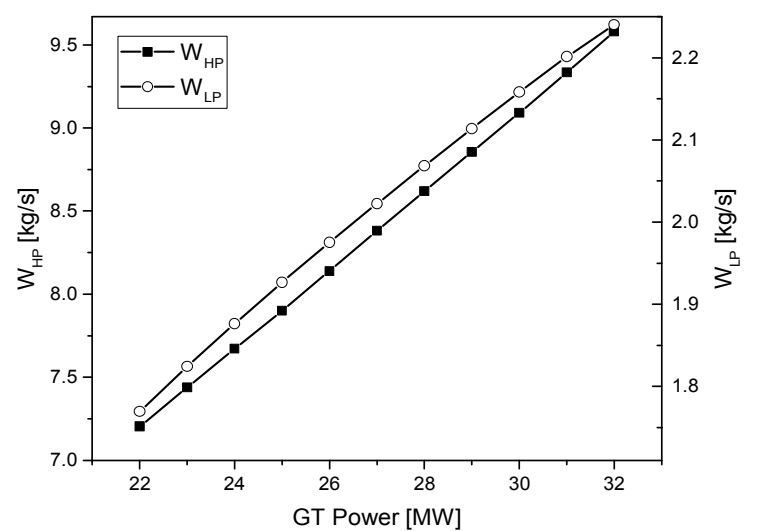

(a)

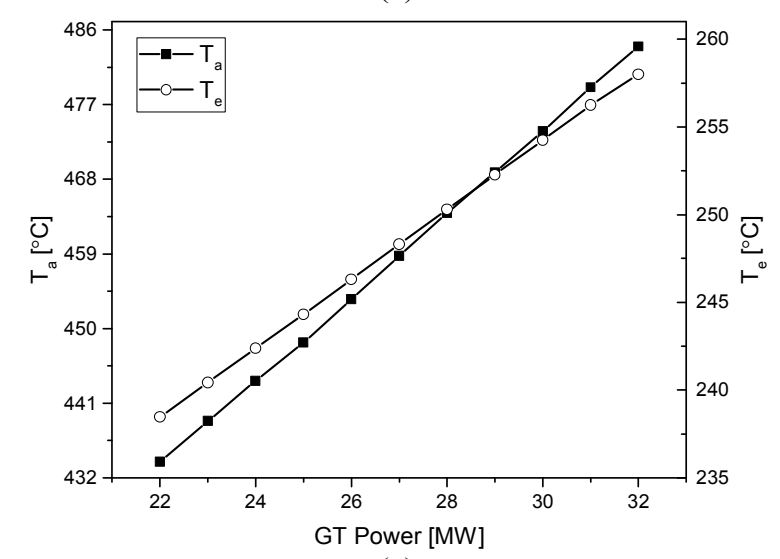

(c)

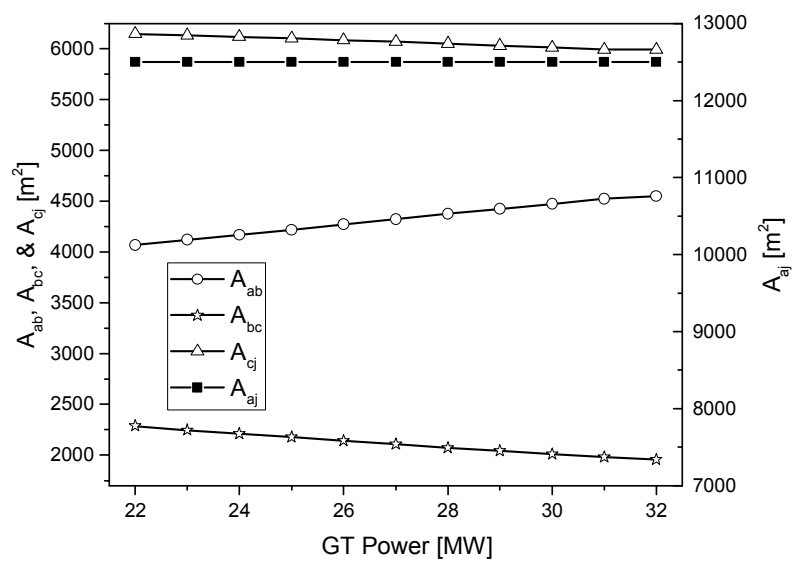

(e)

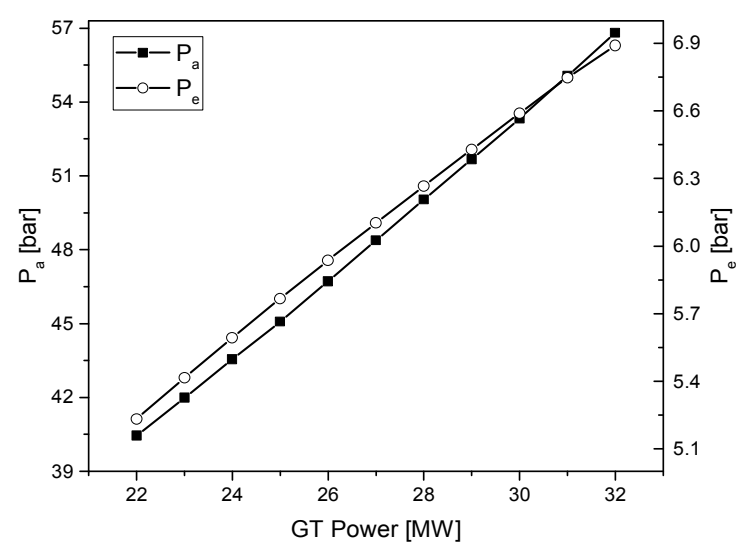

(b)

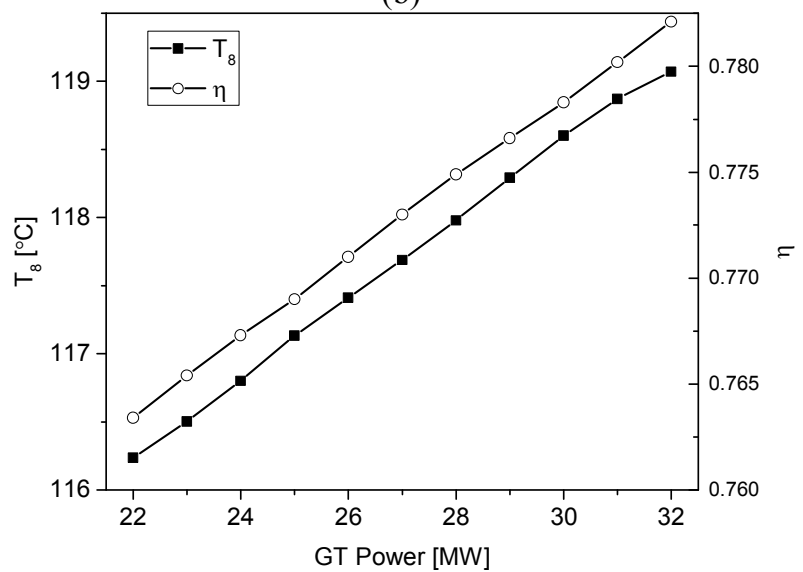

(d)

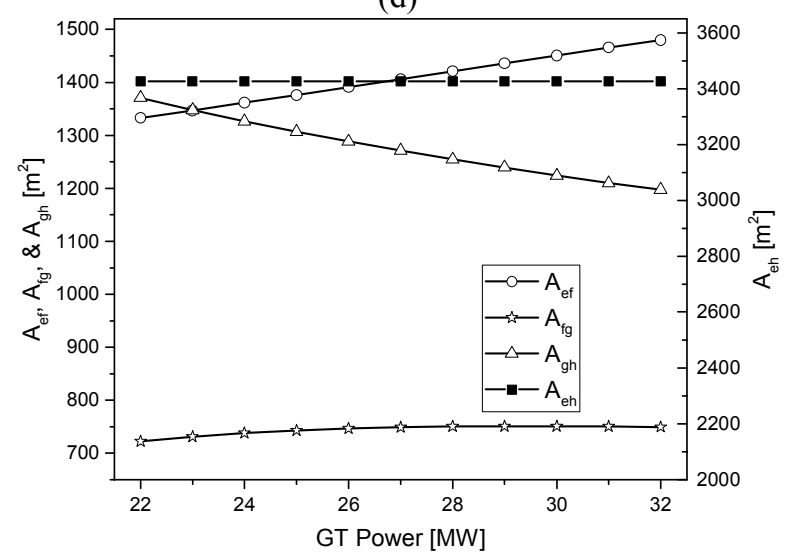

(f)

Fig. 10 Effect of Gas Turbine (GT) Power on OTSG Performance. 


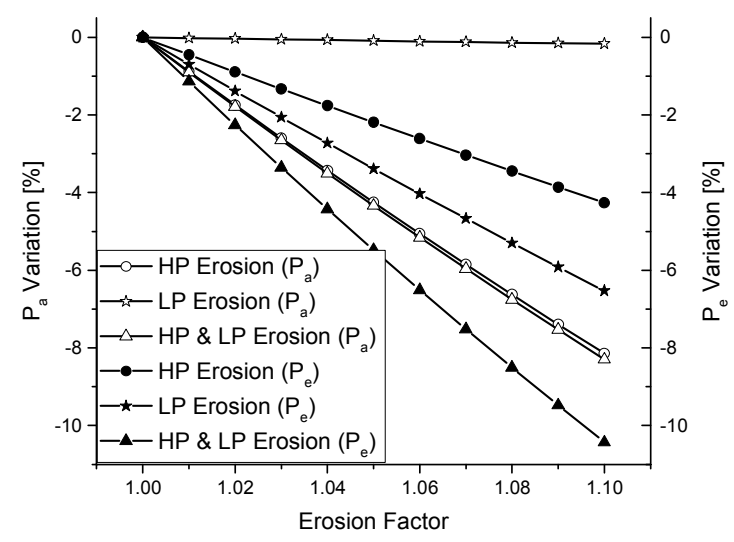

(a)

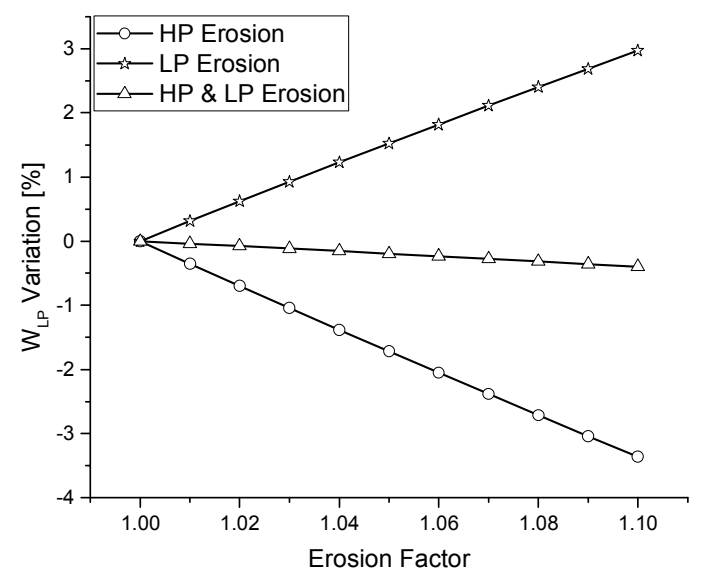

(c)

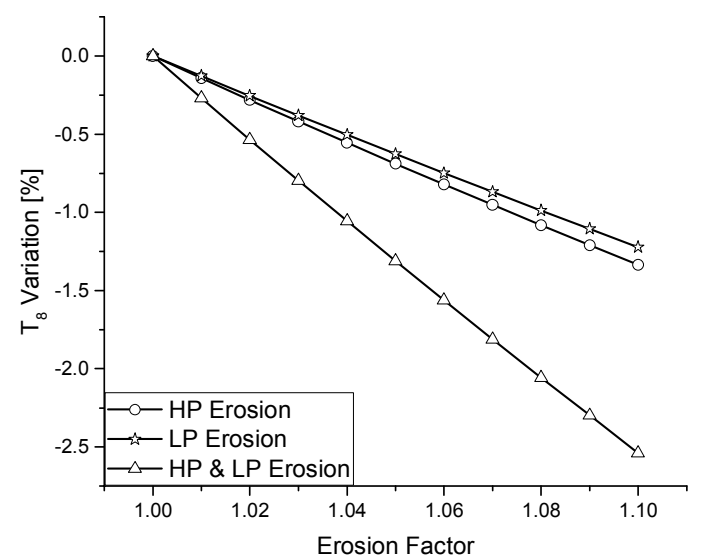

(e)

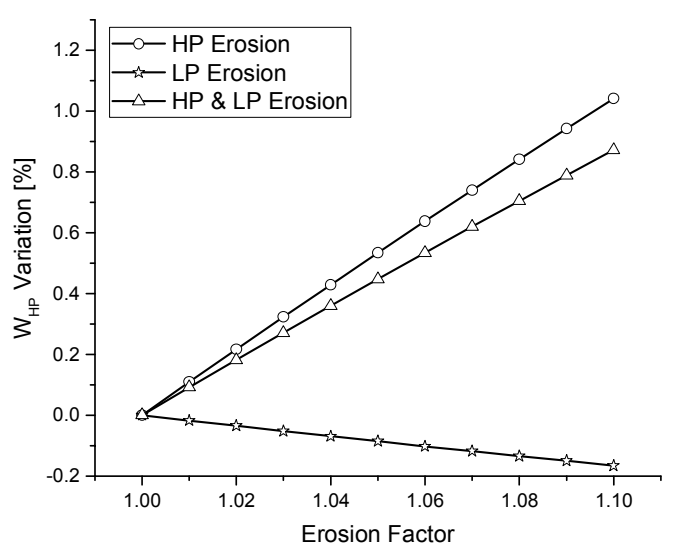

(b)

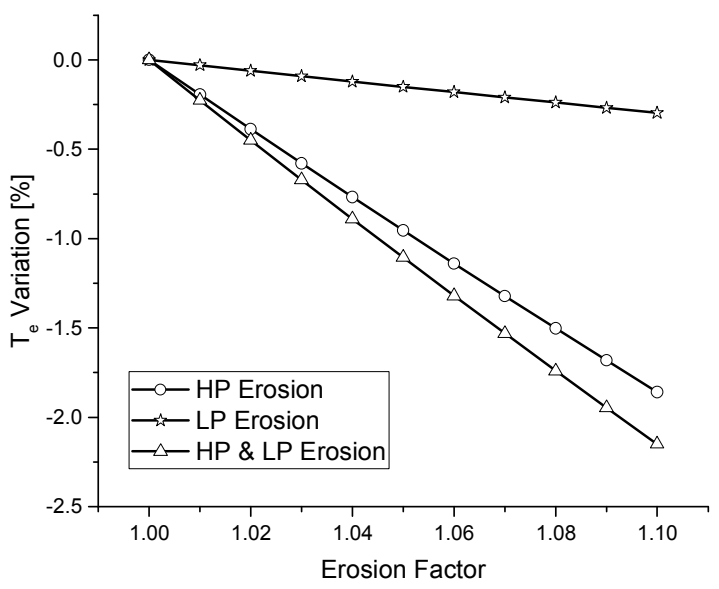

(d)

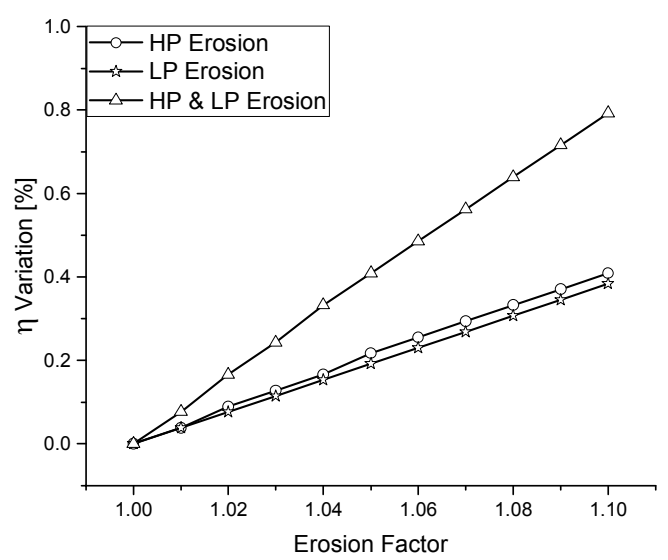

(f)

Fig. 11 Effect of Erosion Factor ( $E F$ ) on OTSG Performance. 
Table 1 CCGT Power Plant Design Point Performance Data (at ISO sea level condition) [12] [26]

\begin{tabular}{cccc}
\hline \hline Symbol & Parameter & Value & Unit \\
\hline$P O_{G T}$ & Gas Turbine Power Output & 32 & $\mathrm{MW}$ \\
$P R$ & Gas Turbine Compressor Pressure Ratio & 23.1 & - \\
$T_{1}$ & Exhaust Gas Temperature & 498.0 & ${ }^{\circ} \mathrm{C}$ \\
$W_{\text {exh }}$ & Exhaust Gas Mass Flow Rate & 89.1 & $\mathrm{Kg} / \mathrm{s}$ \\
$T_{a}$ & HP Steam Temperature & 484.0 & ${ }^{\circ} \mathrm{C}$ \\
$P_{a}$ & HP Steam Pressure & 56.81 & $\mathrm{bar}$ \\
$P P_{H P}$ & HP Pinch & 16.0 & ${ }^{\circ} \mathrm{C}$ \\
$T_{j}$ & HP Feed Water Temperature & 36.0 & ${ }^{\circ} \mathrm{C}$ \\
$T_{e}$ & LP Steam Temperature & 258.0 & ${ }^{\circ} \mathrm{C}$ \\
$P_{e}$ & LP Steam Pressure & 6.89 & $\mathrm{bar}$ \\
$P P_{L P}$ & LP Pinch & 21.0 & ${ }^{\circ} \mathrm{C}$ \\
$T_{h}$ & LP Feed Water Temperature & 36.0 & ${ }^{\circ} \mathrm{C}$ \\
$P O_{S T}$ & Steam Turbine Power Output & 23 & $\mathrm{MW}$ \\
$P_{c o n d}$ & Steam Turbine Condenser Pressure & 0.06 & $\mathrm{bar}$ \\
$\chi$ & Condenser Steam Wetness & 11.70 & $\%$ \\
\hline \hline
\end{tabular}

Table 2 Comparison between Simulation and Measurement at DP [12][26][27]

\begin{tabular}{cccc}
\hline \hline Parameter & Prediction & $\begin{array}{c}\text { Measured } \\
\text { Value }\end{array}$ & Errors (\%) \\
\hline$W_{H P}$ & 9.5809 & $9.58^{[12],[26]}$ & 0.009 \\
$W_{L P}$ & 2.2403 & $2.25^{[12],[26]}$ & 0.431 \\
$T_{8}$ & 119.07 & $120^{[12],[26]}$ & 0.772 \\
$A_{a j}$ & 12500.0 & $12500^{[27]}$ & 0.000 \\
$A_{e h}$ & 3426.03 & $3426^{[27]}$ & 0.000 \\
\hline \hline
\end{tabular}


Table 3 Variables for OTSG DP Performance Calculation

\begin{tabular}{ccc}
\hline \hline Parameter & $\begin{array}{c}\text { Initial } \\
\text { Guess }\end{array}$ & $\begin{array}{c}\text { After } \\
\text { Convergence }\end{array}$ \\
\hline$C f_{d m / d i}$ & 0.35 & 0.4960 \\
$C f_{m n / d i}$ & 0.35 & 0.1903 \\
\hline \hline
\end{tabular}

Table 4 Range of Operating Conditions for 292 Off-Design Points

\begin{tabular}{ccc}
\hline \hline Parameter & Unit & Range \\
\hline$T_{1}$ & ${ }^{\circ} \mathrm{C}$ & $504.5-516.5$ \\
$T_{a m b}$ & ${ }^{\circ} \mathrm{C}$ & $14.3-17.3$ \\
Ambient Pressure & bar & $1.00-1.02$ \\
Relative Humidity & $\%$ & $58.40-88.44$ \\
$W_{\text {exh }}$ & $\mathrm{kg} / \mathrm{s}$ & $75.49-80.44$ \\
Gas Turbine Power & $\mathrm{MW}$ & $26.44-29.39$ \\
$T_{j}$ & ${ }^{\circ} \mathrm{C}$ & $43.4-46.4$ \\
$T_{h}$ & ${ }^{\circ} \mathrm{C}$ & $43.4-46.4$ \\
\hline \hline
\end{tabular}


2019-02-08

Performance simulation of a parallel dual-pressure once-through steam generator

Chen, Yu-Zhi

Elsevier

Chen Y-Z, Li Y-G, Newby MA. Performance simulation of a parallel dual-pressure once-through steam generator. Energy, Volume 173, April 2019, pp. 16-27

https://doi.org/10.1016/j.energy.2019.02.022

Downloaded from Cranfield Library Services E-Repository 